\title{
Challenges of Multiculturalism and Linguistic Pluralism in Nigerian School Setting
}

\author{
ONUORA, NGOZI THERESA \\ Alex Ekwueme Federal University Ndufu-Alike, Ebonyi State, Nigeria
}

\begin{abstract}
Nigeria, like many other African countries, is made up of many cultural groups with diverse cultures making imperative the need to understand and accept each other's differences, in order to foster unity. There is no doubt that both the National Policy on Education as well as the cultural policy for Nigeria all point to the very important position of language in culture and in education, however, these policies do not adequately address the challenges faced in educational institutions situated in a culturally-diverse and multilingual society like Nigeria. Language and culture are inseparable entities forming an interdependent relationship within the multicultural and linguistic pluralistic classroom, which is both a melting pot of languages as well as a myriad of cultural backgrounds. Cultural connections and effective communication enables students to engage in social and interactive activities and allows them to become active participants of the multilingual classroom; hence, this paper addresses some of the major multicultural challenges that both teachers and students of multilingual classrooms face within the Nigerian school setting.
\end{abstract}

Keywords: Multiculturalism, Linguistic Pluralism, Challenges, Nigeria, School.

DOI: $10.7176 / \mathrm{IKM} / 11-4-01$

Publication date:May $31^{\text {st }} 2021$

\section{Introduction}

Language and culture are inseparable, as it is language that distinguishes various societies into the categories of multi-ethnic, multi cultural or multi-lingual. Language is the single most important factor that distinguishes human beings from other creatures of the earth. In a multi-ethnic society like Nigeria, there are bound to be diverse cultures and several languages, and the diversity of cultures has various implications for national development, national cohesion and national consciousness (Ene, 2015). According to Varner \& Beamer (2005), culture and language are intertwined and shape each other. Every time words are chosen, a sentence is formed and a message sent, cultural choices are made. While language helps in communicating with people from different backgrounds, cultural literacy is necessary to understand the language being used. If language is selected without an awareness of the cultural implications, at best, communication may not be effective and, at worst, the wrong message may be sent. Ashworth (1990) defines an indigenous language as the language of the people considered to be the original inhabitants of the area. Bamgbose (1995) puts the number of such languages in Nigeria at about400. This situation clearly sets the country on the multi-cultural and multilingual map. In the same vein, Akeusola (2012) defines multiculturalism as an environment in which differences among people, cultures and groups are recognized, respected, and valued.

In a multicultural society like Nigeria, how do students and their teachers cope in a typical school setting? When we interact with people from other cultural communities, we are interacting with other cultural worldviews. This interaction is deeply tied to hidden networks of meanings, values, and expectations that we still do not fully know or comprehend. So, how can we learn a new culture while communicating with one another? If we do so, does that mean we need to give up and replace our existing culture to 'fit in' to the new culture? These are just a few questions that arise when one is learning in a multicultural society, living and working in another cultural environment, as well as facing intercultural learning challenges. Nevertheless, in multilingual classrooms, the situation is more complex. According to Csillik (2019), there are multiple questions to debate and consider, such as how does a teacher teach effectively in a multilingual classroom where a wide variety of cultures and languages co-exist? Also, is there any superior/inferior culture/language in the classroom, and what language should be the lingua franca? Additionally, what curriculum should be followed, and should "just anyone" who speaks the lingua franca teach without prior experience in a diverse classroom such as this? How can a teacher handle cultural differences in the classroom, and most importantly, how does a teacher integrate all language learners/speakers of different cultures in the learning process, so every student feels like a valuable participant of the learning experience? The above questions are genuine amongst teachers of 'diverse' populations, whose services are constantly needed in a number of multilingual/multicultural classrooms amidst the increasing rate of migration. Therefore, this phenomenon has necessitated the need to examine the challenges of multiculturalism and linguistic pluralism in Nigerian school setting. In this study, the author will provide an overview of multicultural educational setting in Nigeria. The literature will further attempt to identify the peculiar challenges in culturally-diverse school system, and proceed to provide possible tips, based on teaching experiences of teachers of diverse multilingual/multicultural classrooms. Nonetheless, it is imperative to point 
out that there exists a dearth of case studies showing the challenges of multicultural and linguistic pluralism in educational settings in Nigeria.

According to Macleod (2002), culture consists of behaviours related to language, religion, values, standards, and customs that are shared by a group of people and learned from birth. Language is the lubricant of culture. Without language a culture ceases to exist. Nigeria as a multi cultural nation makes it the home of many indigenous cultures and languages. Culture is central to the life of the individual within the group as well as of the group itself, both in a spiritual and intellectual sense.

\section{Literature Review}

Nigeria is unarguably one of the most populous nations in Africa with an estimated population of over 180 million people speaking over 500 languages fragmented into over 250 ethnic groups. The nation covers an area of 923,766 square kilometres that comprises 36 states and the Federal Capital Territory. Thus, Nigeria is heterogeneous in nature both linguistically and culturally (Olagbaju, 2020). In Nigeria, as in other ex-colonial nations, language politics has come to represent two major types of struggle, one against the vestiges of colonialism and the other against the domination of ethnic and language minorities by the larger ethnic groups. The first struggle has led to the rejection of colonial languages in certain domains, the ultimate goal being to reallocate the official status accorded colonial languages to indigenous languages, and the second to ambivalent policies which call for linguistic unification under one or a few indigenous "national" languages, while simultaneously promoting linguistic pluralism and cultural diversity (Akinnaso, 1990). The politics underlying these struggles is particularly evident in the language education policies of the ex-colonial nations of Africa.

Over the decades, Nigeria has experienced a rapid influx into new, culturally different territories across the country and with the mingling of people and cultures, come various forms of communication conflict as culturally different people attempt to live together (Elegbe \& Nwachukwu, 2017). Indeed, as Merkin (2009) points out, the mingling of culturally different people highlights the divergence of perspectives between members of different cultures. Careful considerations of these factors show that the individual cannot but see the world through the limited lens of his culture. He believes his learned behaviour is normal until he encounters a person from a different culture. Thus, when such individuals interact with people from other cultures and experience different behaviours and patterns of communication, a sense of irritation and even anger sets in. This is followed by a breakdown of communication.

Olagbaju (2020) observes that most Nigerian societies, classrooms inclusive, are polarised along religious and ethnic divides and issues concerning religious and ethnic beliefs are common in the country; hence, multiculturalism has serious implications for effective teaching and learning within and outside Nigerian classrooms. Lawal (2019) posits that instruction is mostly conducted in Nigerian pidgin English due to the multicultural nature of classrooms in most states of South-south Nigeria like Edo, Delta, Rivers, Bayelsa, Cross River and Akwa-lbom, classroom. This is because teachers are compelled by the necessity to improvise in the instructional delivery so that no learner will be left behind. Similarly, the content to be learned and choice of illustrations/examples must be seen to be devoid of ethnic or cultural bias. Therefore, the Nigerian Pidgin (NP) is widely used in certain states where minority languages abound without any particular language assigned as the major language (Lawal, 2019).

In 1988, the Federal Government promulgated a Cultural Policy for Nigeria which provides that the culture of Nigeria shall have a direct influence on and be the basis for education, industry, tourism, and technology. The Policy, inter alia, declares as follows:

i. The policy shall serve to mobilize and motivate the people by dissemination and propagating of ideas which promote national pride, solidarity and consciousness.

ii. Promote an educational system that motivates and stimulates creativity and draws largely on the tradition and values, namely: respect for humanity and dignity of labour, and respect for positive Nigerian moral and religious values. Nigeria has a national policy on languages discernable from a number of documents.

In a similar development, to address the dilemma encountered by Nigerian teachers in multilingual/multicultural classrooms, the National Policy on Education (FGN, 2004) states:

The medium of instruction in the primary school shall be the language of the environment for the first three years. During this period, English shall be taught as a subject. From the fourth year, English shall progressively be used as a medium of instruction and the language of immediate environment and French shall be taught as subjects.

The excerpt from these policy documents quoted above affirms the reality of multilingualism/multiculturalism in the Nigerian classroom. Language plays a critical role in education and the NPE (as quoted above) has aptly addressed the multilingual challenges in the classroom. However, the policy has not adequately taken care of multiculturalism that exists in the Nigerian classroom which impedes effectiveness in teaching and learning. The relationship between language and culture is complementary because 
the language of a people serves as a vehicle for the preservation and transmission of their culture from one generation to the other. Multiculturalism, just like multilingualism, is a concrete experience in Nigeria and it is evident in every aspect of the nation's social life.

In another development, Akeusola (2012) puts forward that the philosophy of Nigeria Education centres on a free and democratic society; however the curriculum content of and administration of Nigerian Education are sometimes criticised as being out of tune with the philosophy of education. Okoh (1995) enumerated some of these criticisms to include, lack of ideological orientation that should indoctrinate citizens, lack of local orientation and inadequate Nigerian background, as shown by the gap in the teaching of Nigerian history and culture. The author further stated that these rob citizens of the knowledge that should enable them understand other groups and thus help eliminate ethnic prejudices. Cultural diversity characterizes Nigeria; therefore, whenever one talks of reorientation of teachers in the society, it must have a cultural basis, and it must be amenable to the demands of multicultural societies.

The social realities as portrayed Nigeria reveals that it is an extremely culturally pluralistic socially stratified and ethnically divided country. In spite of the pluralism in Nigeria, most people live in relative isolated enclaves, away from others who are ethnically, socially and culturally different. Individuals from the same ethnic groups live in close proximity to one another, creating largely single race or ethnic group and geographical clusters. These cultural diversities apparently desegregate the communities, and in many unconsciously segregated schools, the students tend to desegregate themselves in social interactions and friendship choices (Akeusola, 2012). Individuals in these groups are therefore more likely to engage in qualitative interactions with people whose culture is like theirs than with people from different ethnic groups. The absence of close and significant interactions across ethnic, social and cultural lives may reinforce stereotypes and cause individuals to be suspicious and distrustful, even fearful of those who are perceived to be different from them. As such, multicultural education is needed to help reverse these trends and attitudes by teaching youth about the culture of different groups and by providing opportunities for individuals from diverse background to learn, live and work together.

\section{Challenges of Multiculturalism and Linguistic Pluralism in Nigerian School Setting}

\section{i. Cultural and Demographic Issues and Problem Areas}

Worldwide, multicultural education is a huge concern, not limited to one culture or society. In Nigeria, the constitution allows for freedom of movement and association; hence, people settle in any part of the country for which they so desire. For this reason, diverse cultural communities have become interconnected due to the changing demographic flow. For this reason, a typical school setting in a multicultural society has students from different parts of the country. These students have already-learned or established hidden differences, such as values, norms, assumptions, religious views, among others (Csillik, 2019). While their social and individual identities might be seen differently in the host culture due to existing stereotypes, in such a diverse multilingual and multicultural school setting, 'personality words' should not be used to describe a particular culture in order to avoid preference of one dominant culture over the others, and the preference of one dominant language over the others. This is because, by using such words as, "emotional", "shy", "reserved", "friendly", "hard-working" or "lazy", to describe a particular ethnic group, we build a hidden cultural bias into our description because the words are judgmental rather than simply being descriptive. However, the question becomes: what should the language of instruction in a multilingual classroom be? where maybe the "dominant" language is not even spoken by any student in the classroom? For example, what if everyone in the class learned the "dominant" language as their second, or even third, language? Many times, English will be the language of choice, as it is the lingua franca of the globalized world (Grucza, Olpińska-Szkiełko, \& Romanowski, 2016). Meanwhile, any language could be used as the lingua franca with anyone from any community. Then, what happens to lowincidence languages that are also presented in a multilingual classroom? Does it mean that the speakers of these low-incidence languages may get marginalized in the classroom since their native language is not the "dominant" one in the culturally diverse classroom? Therefore, all languages should be equally accepted in the multilingual/multicultural classroom and represented in the community since it is the indisputable right of all human beings to access education in their own language.

However, another pertinent question that arises is; how can one teacher integrate multiple languages in one classroom setting to represent all humans' rights at the same time? Also, how can participants of the multilingual/multicultural classroom deal with the constant and rapid changes of the classroom's cultural diversity due to the continuous flow of migration? Csillik (2019) therefore suggests that empathy is the key. She states that empathy is the ability to view the world using new perceptual frameworks. It is a natural by-product of successful co-existing relationships between participants of the multilingual/multicultural classrooms, and is highly needed in the difficult process of learning a new culture (or multiple cultures at the same time), which can be accomplished only through direct, sustained, and a very deep involvement. In a multilingual/multicultural classroom, students not only have contact with one culture; but also, with several other low-incidence cultures, 
consequently, only through a high level of empathy, can cultural differences and similarities be understood in a multilingual/multicultural classroom.

As such, it is essential for children to learn the attitudes and beliefs that support creation of a welcoming, affirming environment that respects and appreciates all languages and cultures.

\section{ii. Teacher Related Issues and Problem Areas}

According to Csillik (2019), one of the challenges faced by teachers who teach in a multilingual/multicultural classroom is finding ways to support the vast variety of home languages of the students. Several teachers might feel overwhelmed with the amount of different low-incidence languages that are represented in the classroom. Therefore, fostering a child's home language starts with a relationship with the families. Teachers must show that they value and respect all languages and cultures in the class and that they are eager to communicate with all families equally. Very often it is not easy to find a way to communicate with families in their home languages. As such, teachers must find innovative ways, such as making connections with others in the community who also speak the same languages as the children's' families. Furthermore, it is always positive to show one's own special spirit of adventure by learning and using some words of the low-incidence languages, such as greetings, requests for help, terms of comfort and encouragement. Hanging welcoming signs around the classroom in the different languages represented in the classroom, translating the subjects in the flow of the day, so multilingual students can follow the routine of the day; or labeling objects in different languages around the classroom to create a culturally responsive print-rich environment, are just some of the creative ideas that teachers might follow. In the case of children, it is always welcoming to invite speakers to the class who speak the children's home languages or volunteers to help to translate letters, forms, and other ongoing written communications into the child's language.

Moreover, García \& Wei (2014) observe that allowing "code-switching” as a pedagogical practice in the classroom to be able to choose the language in which students can convey meaning in the most accurate way, mostly in the form of speaking and writing, makes students comfortable from the very beginning of their learning. Translanguaging, or, "code-switching" is the act of using different languages interchangeably, in order to overcome language constraints, to deliver verbal utterances or written statements effectively, and, to ultimately achieve successful communication (Csillik \& Golubeva, 2017). As a result, encouraging students to use their home languages with peers during work time, in groups, during independent work time in writing assignments, responses to literature, or during free writing, helps them claim some ownership in the educational process, show a stronger understanding of the subject area, and express individuality. Additionally, by using the home language, students show their options and preferences to convey their personal identity, their belonging to a social group or minority (Golubeva \& Csillik, 2018). Code-switching provides students with a link to "home", which is extremely comforting in an environment where newcomer students face the 'cultural shock' of the new environment (Golubeva \& Csillik, 2018; Csillik \& Golubeva, 2019). Additionally, teachers can support students further if they provide multilingual reading materials, if available, from community libraries, or give permission to produce projects and assignments in their home language. This can make students feel valued and welcomed in their new environment. Importantly, vigilance is required from teachers while teaching in a multilingual/multi-cultural classroom, in order to ensure that all the different languages in the classroom are balanced.

In continuation, Derman-Sparks \& Olsen Edwards (2010) propagates the principle of anti-bias education that highlights the need on the part of the teacher to address the existing cultural differences in the classroom. They emphasis that teachers should talk about the similarities and differences of different languages and cultures (music, traditions, household customs, religious views, etc.) and everyday experiences. Csillik (2019) maintains that there is no "onesize-fits-all" learning environment to support multilingual/multicultural students; therefore, every teacher is encouraged to take risks and try what works the best for the given multilingual/multicultural population he/she works with. On the other hand, it is imperative to add that any teacher regardless of their cultural background must be culturally responsive and have an abundance of cultural awareness, motivation, patience and high level of empathy. Exhibiting tolerance, being aware of one's own biases and prejudices (as well as others), using questionnaires and surveys to learn about the students and their background cultures and knowledge of other cultures, allowing collaborative and social learning in the class to acquire interest and curiosity about 'otherness'; and providing different opportunities for learning based on the background culture, are just some of the ways that educators can show that they are culturally responsive.

Lastly, a concerning problem for teachers of multilingual/multicultural students is the lack of opportunities for relevant workshops, quality training, and professional development. This is due to the limited number of skilled, experienced, knowledgeable and innovative trainees or teachers that could be presenters of these important learning opportunities. These workshops could appropriately and consciously familiarize teachers of multilingual/multicultural learners with current trends, best practices, and developments in the field of anthropology, sociology, social and cross-cultural psychology, and semiotics. Most importantly, the urgent need for teachers to learn from the results of actual studies carried out on the field by researchers, would be beneficial 
to guide teachers' every day practices in the multilingual/multicultural classrooms to further implement practices with proven theoretical findings behind, instead of only relying on one's own and already implemented practices with coworkers locally or virtually through teacher created websites on-line (Csillik, 2019).

\section{Students Related Issues and Problem Areas}

Students react differently to a new environment. Some might be able to deal with adjusting to these changes rapidly, but some might act "funny" or "weird" when experiencing some degree of 'cultural shock' for the first time. As Romanowski (2017) describes this phase "firstly, learners experience strangeness of their interlocutors and secondly, their contact with unfamiliar people challenges their own understanding of reality and often makes them discover a stranger in themselves." The tremendous amount of new information, the language barrier, the cultural gap, the feeling of homesickness, boredom, and anxiety are just a few things children might feel in their unfamiliar environment. Besides, some students, because of not being able to communicate effectively with others, might develop selective mutism that affects their future ability to successfully communicate with others. After the period of 'cultural shock', students develop coping skills; they begin to express themselves adequately in class and start forming friendships outside their own cultural or linguistic group. They might choose to integrate, by adopting some of the values, beliefs, and customs of the new culture while maintaining their own culture. They learn to value the new culture and be able to move comfortably between the two (languages, cultures). These stages of acculturation might overlap and differ from student to student. Accordingly, students might cope with cultural differences in various ways: with resistance, with acceptance, or with adaptation. They can resist, consciously or unconsciously, the internal change in response to the patterns or expectations of the new environment. Resistance is considered as being dismissive of the differences, and as a way to uphold the primacy of one's internal cultural patterns. Acceptance on the other hand implies the willingness to perceive the cultural differences without necessarily implying a change in order to better imply one's internal cultural pattern with those of the environment.

Again, some students might experience two further phases: denial and defense. In the denial phase, they do not even recognize that cultural differences exist. They are in complete physical and psychological isolation and their reality of the other cultural viewpoints does not exist at all. The defense phase occurs when they feel that the new cultural viewpoints are a threat to them, and they create specific strategies to deal with this threat. In this phase, they notice cultural differences, but they evaluate them negatively.

The next problematic area related to students is that since students come from different parts of the country in a multicultural/multilingual class, these students often have a different prior level of education. It is difficult enough to teach different students, but it makes the situation even more challenging when students might have interrupted formal education or might have never even been enrolled in any educational institute before arriving in the multilingual/multicultural classroom. Another problematic area is the question of 'gender equity'. Specifically, boys and girls are taught with different approaches in certain cultures and religions, which can give children the perception that they are different and deserve different treatment in their new environment. Also, in certain cultures, males are seen and treated with more respect than their female peers, which might lead to the problems of male students of certain cultures disobeying female teachers.

\section{Curriculum Related Issues and Problem Areas}

Curriculum design for multilingual/multicultural classes is also one of the problematic areas in diverse communities (Csillik, 2019). Curriculum used in multilingual/multicultural classes should reflect a variety of different cultures in the form of culturally responsive collection of literary texts accompanied with illustrations of different ethnicities or accepting and encouraging different ways of solving problems. Unfortunately, the availability of such culturally responsive curriculum is still challenging, even though this kind of curriculum is currently in high demand. According to Umera-Okeke (2016), English textbook should not be filled with foreign names such as John, Peter, Bernard but names taken from all ethnic cultures of Nigeria such as Ngozi, Amaka, Chinedu (from Igbo); Amina, Aishatu, Mohammed (from Hausa); Tope, Segun, Adebola (Yoruba), Essien, Okon, Tega Priye, Belema from the minority languages, to mention but a few. Sumaryono and Wilma (2004) supported this view by stating that understanding and supporting the cultural norms of diverse learners help to create a safe and nurturing environment, which motivates students to take the necessary risks to be successful. Therefore, it is essential to find meaningful ways to incorporate the richness of students ${ }^{\text {ee }}$ cultural backgrounds into the curriculum. Umera-Okeke and Ezekwe (2014) therefore suggested that "teachers should incorporate the richness of students' cultures in the curriculum. They can do this by using different languages to say key words, which can be written on the board and learned by all the students in the classroom."

\section{Assessment Related Issues and Problem Areas}

Teaching and assessment are linked together in any educational setting; so, the lack of culturally authentic resources in multilingual/multicultural classrooms also translates to the lack of culturally authentic assessments 
as well. In a multilingual/multicultural setting, it is one of the mostly debated challenges yet to be resolved. For instance, Csillik (2019) avers that in many educational settings, there is no translated version of content-area based standardized tests (e.g. Mathematics, Science, Social Studies) in minority languages, or an opportunity for students to use oral translators of these minority languages while taking the content-area standardized tests.

Consequently, as curriculum documents would need to include cultural content, assessment documents should do so accordingly. The overall reason for using authentic materials in multicultural classrooms, according to Calpro (2007) is because authentic materials help students to bridge the gap between the classroom and the outside world. Many students enroll in school because they have personal long-term goals that involve education, such as becoming an engineer or business owner. In working with new students, teachers need to identify why students have come to class. When teachers know learners' motivations, they can target instruction to meet those goals. A key way to help learners reach their goals is to use authentic, goal-directed materials.

\section{Way Forward}

The only tool that teachers of multilingual/multicultural students can use to find possible solutions is to implement some of the everyday practices and strategies in the culturally and linguistically diverse classrooms. Accordingly, some effective strategies as recommended by Csillik (2019) are as follows:

i. Getting to know your students.

ii. Building cultural awareness, creating a culturally welcoming environment.

iii. Building and activating background knowledge.

iv. Using scaffolding strategies such as, class routines and rules; contextualization, such as TPR (total physical response) method, manipulatives, visuals, graphic organizers, and technology; modeling, such as, questioning techniques, think aloud, real-life examples, extended wait time, etc.

v. Building vocabulary through authentic and meaningful experiences with words teaching academic language.

vi. Allowing code-switching practices freely flowing.

vii. Involving all families in their child's education.

viii. Using alternate ways of assessment.

These strategies can be implemented rigorously throughout every day practices of the teacher combined with anti-bias principles spiced up with advocacy, empathy, motivation and patience.

\section{Conclusion/Recommendation}

The challenges of multilingual and multicultural educational environment are just too many. There is therefore a strong necessity for further inquiries and research studies into this field. This can ensure that best practices are churned out for both and teachers and students in multilingual/multicultural classrooms. Accordingly, much still needs to be done to develop a more knowledgeable, culturally responsive, diverse students and teachers.

Nonetheless, as a coping strategy, teachers should endeavour to gain a wide range of knowledgeable skills that can be implemented in the multilingual/multicultural classrooms during their every day practices. They should implement their knowledge-based expertise while simultaneously promoting an anti-bias environment. The acceptance of all students regardless of their cultural, educational, and social-emotional background is essential. Teachers should learn to be an embodiment of values; beliefs and behaviors that will enable them navigate through the challenges of multicultural/linguistic pluralist educational settings.

\section{References}

Akeusola, B. N. (2012). Social Studies Teachers' Perception of the need for Multicultural Education Programme in Junior Secondary Schools in Lagos state, Nigeria. (Masters Dissertation).

Akinnaso, F. N. (1990). The politics of language planning in education in Nigeria. Word, 41(3), 337-367

Ashworth, M. (1990). Beyond methodology: Second language Teaching and the Community. Cambridge: Cambridge University Press

Bamgbose, A. (1995). English in the Nigerian Environment. In New English: A West African perspective (ed.) Ibadan: Mosuro Publishers

CALPRO Online.org, (2007). Professional Development Fact Sheet No 1: Authentic materials. Retrieved May 1, 2016 from www.calpro-online.org/documents/AuthenticMaterialsFinal

Csillik, E. (2019). Intercultural Challenges of Teaching Multilingual/Multicultural Classrooms: Intercultural Foreign Language Teaching and Learning in Higher Education Contexts. USA, IGI Global.

Csillik, E. \& Golubeva, I. (2017). The current 'state of the art' in researching codeswitching in multilingual classroom. In C. A. Huertas-Abril (Ed.), La educación, clave para el entendimientomundial (11-23). Córdoba, Spain: UCOPress, Servicio de Publicaciones de la Universidad de Córdoba.

Csillik, É. \& Golubeva, I. (2019). Játék a szavakkal: Transzlingválisgyakorlatok a new York iangolmagyarkétnyelvüóvodáskorúkisgyerekekcsoportjában. In $20^{\text {th }}$ SSOP. Academic Press. 
Derman-Sparks, L. \& Olsen Edwards, J. (2010). Anti-Bias Education for Young Children and Ourselves. Washington, DC: NAEYC.

Elegbe, O. \& Nwachukwu, I. (2017). A Cross-cultural Analysis of Communication Patterns between Two Cultures in Southwest Nigeria. Inkanyiso Journal of Humanities \& Social Sciences, 4.

Ene, F. (2015). English Language Teaching in a Multi-Cultural Society: The Case of Nigeria.

Curriculum Organization of Nigeria Conference, 23(4). University of Lagos, Curriculum Organization of Nigeria (CON).

Federal Government of Nigeria, (2004). National Policy on Education. Lagos: NERDC Press.

García, O. \& Wei, L. (2014). Translanguaging. Language, Bilingualism and Education. New York: Palgrave Macmillan.

Grucza, S., Olpińska-Szkiełko, M. \& Romanowski, P. (2016b). Advances in Understanding Multilingualism: A Global Perspective. Warschauer Studien zur Germanistic und zur Angewandten Linguistik. New York: Peter Lang GmbH.

Lawal, S. O. (2019). Impact of Nigerian Pidgin English on Senior Secondary School Students'

Competence and Performance in English Composition in Military and Paramilitary Schools in Ibadan. B.A Project submitted to English Department, National Open University of Nigeria.

Macleod, G. (2002). Cultural Considerations: A Guide to Understanding Culture, Courtesy and Etiquette in South African Business. Claremont: Spearhead.

Merkin, R. (2009). Cross-cultural Communication Patterns - Korean and American Communication. Human Communication, 12 (2), 199-213.

Olagbaju, O.O. (2014). Multilingual education in Nigeria: Policy provisions, reality on ground, challenges and solutions. Journal of Education and Practice, 5(6), 66 - 73.

Okoh, J.D. (1995). The Nigerian world-view and its exemplications in education. Nigerian Journal of Educational Philosophy, 6(1), 65 - 75.

Romanowski, P. (2017). Intercultural Communicative Competence in English Language Teaching in Polish State Colleges. Newcastle upon Tyne, UK: Cambridge Scholars Publishing.

Umera-Okeke, N. P. (2016). Transculturalism: A Path to the Integration of the Multilingual/Multi-ethnic Learners of English as a Second Language in Nigeria. African Research Review, 10(5), 126-136.

Varner, I. \& Beamer, L. (2005). Intercultural Communication in the Global Workplace. 3rd edition. New York: McGraw-Hill/Irwin. 